\title{
Possible involvement of tumor-producing VEGF-A in the recruitment of lymphatic endothelial progenitor cells from bone marrow
}

\author{
MASAHIRO TAWADA ${ }^{1,3}$, SHIN-ICHIRO HAYASHI ${ }^{2,4}$, YUKA IKEGAME ${ }^{2}$, \\ SHIGERU NAKASHIMA ${ }^{2}$ and KAZUHIRO YOSHIDA ${ }^{1}$
}

\begin{abstract}
Departments of ${ }^{1}$ Surgical Oncology and ${ }^{2}$ Cell Signaling, Gifu University Graduate School of Medicine, Gifu, Gifu 501-1194;
${ }^{3}$ Department of Surgery, Gifu Prefectural General Medical Center, Gifu, Gifu 500-8717; ${ }^{4}$ Division of Hypertension and Nephrology, National Cerebral and Cardiovascular Center, Suita, Osaka 565-8565, Japan
\end{abstract}

Received May 27, 2014; Accepted July 17, 2014

DOI: $10.3892 /$ or.2014.3499

\begin{abstract}
Lymphatic metastasis of human malignant adenocarcinomas is a critical determinant of prognosis. Lymphangiogenesis, the growth of lymphatic vessels, is closely involved in lymphatic metastasis. However, the mechanisms of tumor lymphangiogenesis are not clearly understood. In a previous study, we showed that human gastric cancer MKN45 cells organize neighboring lymphatic vessels via recruitment of bone marrow-derived lymphatic endothelial progenitor cells in a nude mouse xenograft model. The present results also indicated that human colorectal cancer LS174T and breast cancer SK-BR-3 cells promoted lymphangiogenesis as well as the recruitment of lymphatic endothelial progenitor cells from bone marrow. Among growth factors, which are reported to be involved in lymphangiogenesis, only vascular endothelial growth factor (VEGF)-A was extensively secreted by these three types of adenocarcinoma cells in culture. The well-characterized lymphangiogenic factors VEGF-C and VEGF-D in the culture medium of these three types of adenocarcinoma cells were below the detectable levels in ELISA assay. Secretion of epidermal growth factor (EGF) and hepatocyte growth factor (HGF) was not detected. In in vitro culture assay, VEGF-A directly induced the differentiation of bone marrow mononuclear cells into LYVE-1-positive lymphatic
\end{abstract}

Correspondence to: Dr Masahiro Tawada, Department of Surgery, Gifu Prefectural General Medical Center, 4-6-1 Noisshiki, Gifu, Gifu 500-8717, Japan

E-mail: tawada0316@yahoo.co.jp

Abbreviations: EGF, epidermal growth factor; GFP, green fluorescent protein; HGF, hepatocyte growth factor; LYVE-1, hyaluronic acid receptor-1; PFA, paraformaldehyde; VEGF, vascular endothelial growth factor; DAPI, 4',6-diamidino-2-phenylindole

Key words: human adenocarcinoma, lymphangiogenesis, VEGF-A, bone marrow, lymphatic endothelial progenitor cells endothelial lineage cells. These data collectively suggest the possibility that VEGF-A-rich human adenocarcinomas induce tumor lymphangiogenesis via recruitment of lymphangiogenic endothelial progenitor cells from bone marrow.

\section{Introduction}

The presence of lymphatic metastasis to regional lymph node is particularly important for cancer prognosis in common human cancers, including gastric, colon and breast adenocarcinomas (1). Thus, the lymphatic vascular system correlates closely with tumor metastasis $(2,3)$. The recent identification of lymphatic endothelial specific markers, such as hyaluronic acid receptor-1 (LYVE-1) (4) and podplanin (5), has greatly increased attention on how lymphangiogenesis, the growth of lymphatic vessels, is regulated in the tumor microenvironment. Tumor-induced lymphangiogenesis is mediated by lymphangiogenic growth factors $(2,3)$. The involvement of vascular endothelial growth factor (VEGF)-C and VEGF-D in cancer progression and in tumor-associated lymphatic vessel growth has been demonstrated in several experimental systems (6-8). A role for VEGF-A in tumor-mediated lymphangiogenesis has also been reported $(9,10)$. We have developed a tumor xenograft experimental model using chimeric nude mice with green fluorescent protein (GFP)-positive bone marrow cells (11). In this xenograft model, we showed that human gastric cancer MKN45 cells induced tumor lymphangiogenesis via recruitment of lymphatic endothelial progenitor cells from bone marrow. In the present study, using the same xenograft model, human colorectal cancer LS174 and human breast cancer SK-BR-3 cells also promoted lymphangiogenesis and the recruitment of lymphatic endothelial progenitor cells from bone marrow. These three human adenocarcinoma (gastric cancer MKN45, colorectal cancer LS174 and breast cancer SK-BR-3) cells predominantly produced VEGF-A with negligible secretion of VEGF-C and VEGF-D. VEGF-A, as well as well-known lymphangiogenic factors, VEGF-C and VEGF-D (2,3), induced the expression of LYVE-1, a specific lymphatic endothelial marker, in bone marrow mononuclear cells in culture. The present study shows the role of VEGF-A, 
produced by adenocarcinomas, in the tumor lymphangiogenesis via recruitment of lymphatic progenitor cells from bone marrow.

\section{Materials and methods}

Materials. LS174T colorectal cancer (12) and SK-BR-3 breast cancer cells (13) were obtained from American Type Culture Collection(ATCC)(Manassas, VA,USA).MKN45 gastric cancer cells (14) were from RIKEN BioResource Center (Tsukuba, Japan). C57BL/6J and C57BL/6-Tg-CAG-EGFP mice were from SLC (Shizuoka, Japan). CAnN.Cg-Foxn1 ${ }^{\text {nu}} / \mathrm{CrlCrlj}$ nude mice were from Charles River Laboratories (Yokohama, Japan). ELISA kits and recombinant human VEGFs were from R\&D Systems (Minneapolis, MN, USA). Antibody against mouse LYVE-1 was from Santa Cruz Biotechnology (Santa Cruz, CA, USA). Anti-mouse CD34 antibody was from Hycult Biotech (Uden, The Netherlands). Alexa Fluor 594-conjugated antirabbit secondary antibody, SuperScript VILO cDNA Synthesis kit and 4',6-diamidino-2-phenylindole (DAPI) were from Invitrogen (Carlsbad, CA, USA). Histopaque-1083 was from Sigma (St. Louis, MO, USA). PCR primers and SYBR Premix Ex Taq II were from Takara Bio, Inc. (Osaka, Japan). RNeasy Plus Mini kit was from Qiagen (Tokyo, Japan). Type I collagencoated dishes were from Iwaki (Tokyo, Japan). Tissue-Tek OCT compound was from Sakura Finetek (Tokyo, Japan). EBM-2 medium was from Lonza (Walkersville, MD, USA). RPMI1640 medium, antibiotic-antimycotic and fetal bovine serum (FBS) were from Life Technologies (Grand Island, NY, USA). Other chemicals were of the highest quality available.

Culture of human adenocarcinoma cells. MKN45 gastric cancer, LS174T colorectal cancer and SK-BR-3 breast cancer cells were cultured in RPMI-1640 medium supplemented with $10 \%$ FBS and $1 \%$ antibiotic-antimycotic.

ELISA assay. The culture media of human adenocarcinoma cells were collected after $72 \mathrm{~h}$ in culture. Contents of VEGF-A, VEGF-C, VEGF-D, epidermal growth factor (EGF) and hepatocyte growth factor (HGF) were determined by speciesspecific ELISA kits as previously described (15).

Bone marrow-transplanted chimera mice. All animal procedures were carried out according to a protocol approved by the Animal Care and Use Committee of Gifu University Graduate School of Medicine. GFP-positive bone marrow cells were obtained from age-matched 6 week-old C57BL/6-Tg-CAGEGFP mice by flushing the femurs and tibias with Hanks' balanced salt solution, and mononuclear cells were isolated by density gradient centrifugation using Histopaque-1083 (16). The recipient nude mice, CAnN.Cg-Foxn $1^{\text {nu}} / \mathrm{CrlCrlj}$, were lethally irradiated with $8.0 \mathrm{~Gy}$, and received $6 \times 10^{6}$ donor GFP-positive bone marrow mononuclear cells intravenously (11). Bone marrow cells from 6 week-old C57BL/6J mice were used as a negative control for GFP-positive donor cells. At 4 weeks after bone marrow transplantation, mice were used for tumor implantation models. To determine the transplantation efficiency of GFP-positive bone marrow, tail peripheral blood $(10 \mu \mathrm{l})$ or bone marrow from recipient nude mice was collected 3 weeks after tumor implantation, and
GFP-positive cells spread on cover slides were analyzed by fluorescent microscopy.

Murine tumor model. At four weeks after bone marrow transplantation, $2 \times 10^{6}$ cells were subcutaneously injected into chimeric nude mice. At 3-8 weeks after tumor cell injection, mice were anesthetized, perfused with $0.1 \mathrm{M}$ phosphate-buffered saline (PBS; $\mathrm{pH} 7.40$ ) followed by $2 \%$ paraformaldehyde (PFA) in PBS and sacrificed. The tumor area was removed, fixed for $2 \mathrm{~h}$ with $2 \%$ PFA in PBS, and stored frozen in OCT compound (11).

Immunofluorescent staining. The cryostat sections $(6 \mu \mathrm{m})$ of tumor tissues were immunostained with the primary antibody, rabbit anti-mouse LYVE-1 (1:100). The sections were next incubated with Alexa Fluor 594-conjugated anti-rabbit secondary antibody (1:200) and DAPI. Images were analyzed using a BIOREVO immunofluorescence microscope (Keyence, Osaka, Japan). To evaluate lymphatic vessel density or the proportion of GFP/LYVE-1 double-positive cells, we used the inverted-gray scale images of all data (nine fields in each sections), and calculated the total area positive for LYVE-1 or the area double-positive for GFP/LYVE-1 using NIH ImageJ software. To elucidate the histological structure positively stained with LYVE-1 or GFP, light hematoxylin staining was performed on the sections near the immunostained sections. Each result was obtained in at least 4 separate experiments.

Bone marrow cell culture and immunofluorescent cell staining. Bone marrow mononuclear cells were collected from $\mathrm{C} 57 \mathrm{BL} / 6 \mathrm{~J}$ mice as described above. Cells plated onto type 1 collagen-coated dishes and cultured in EBM-2 medium in the absence or presence of recombinant human VEGF-A $(50 \mathrm{ng} / \mathrm{ml})$, human VEGF-C $(150 \mathrm{ng} / \mathrm{ml})$ or mouse VEGF-D $(150 \mathrm{ng} / \mathrm{ml})$. For immunofluorescent staining, cells were fixed with $2 \%$ PFA for $20 \mathrm{~min}$ at room temperature and were stained with rabbit anti-mouse LYVE-1 (1:100) primary antibody for $2 \mathrm{~h}$ at room temperature. Cells were next incubated with Alexa Fluor 594-conjugated anti-rabbit secondary antibody (1:200) at room temperature for $2 \mathrm{~h}$, and also counterstained with DAPI for $2 \mathrm{~min}$. Images were analyzed using a BIOREVO immunofluorescence microscope.

Quantitative real-time RT-PCR. Total RNA was extracted from bone marrow mononuclear cells using an RNeasy Plus Mini kit and $0.5 \mu 1$ of RNA was reverse transcribed to cDNA using a SuperScript VILO cDNA Synthesis kit. cDNA was amplified with SYBR Premix EX Taq II and the following primers: murine LYVE-1 (sense, 5'-CAAAGCCTATTGCCACAACTCATC-3' and antisense, 5'-AGTAGGCGCTGCTGACA-3') and mouse $\mathrm{ACTB} / \beta$-actin. ACTB $/ \beta$-actin transcripts were measured simultaneously in all reactions as internal controls. Up to 40 PCR cycles with an annealing temperature of $60^{\circ} \mathrm{C}$ were performed for cDNA amplification. Relative expression values were calculated from the cycle threshold $(\mathrm{Ct})$ as previously described (17).

Statistical analysis. Each result was obtained in at least 5 separate experiments. All values are expressed as means \pm SEM. Values were analyzed using one-way analysis of variance, and 


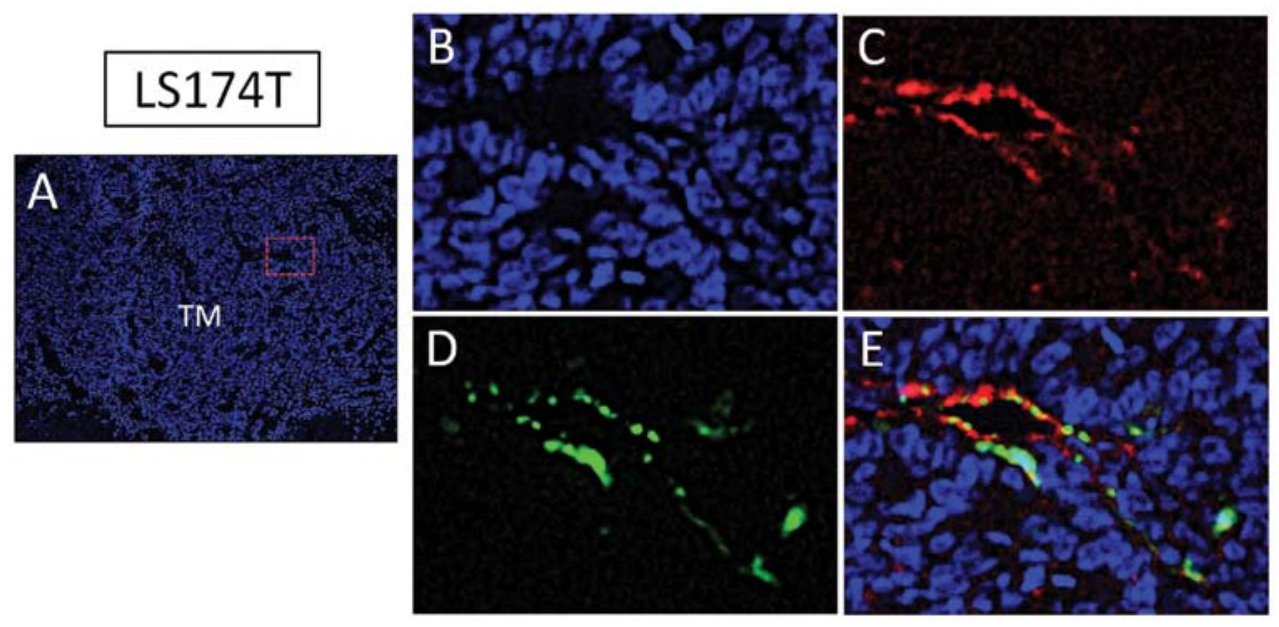

Figure 1. Human colorectal cancer LS174T cells recruit lymphatic endothelial lineage cells from bone marrow. Human colorectal cancer LS174T cells $\left(2 \times 10^{6}\right.$ cells) were xenografted to chimeric nude mice bearing GFP-positive bone marrow. Three weeks after tumor implantation, mice were sacrificed and peritumoral tissues were histologically analyzed. (A) Representative images of tumor mass. (B-E) Representative lymphatic vessels around LS174T tumor mass, (B) stained with DAPI, (C) LYVE-1 (red), (D) GFP (green) and (E) merge images of C and D. Results shown are representative from 5 mice. DAPI, 4',6-diamidino-2-phenylindole; LYVE-1, hyaluronic acid receptor-1; GFP, green fluorescent protein.

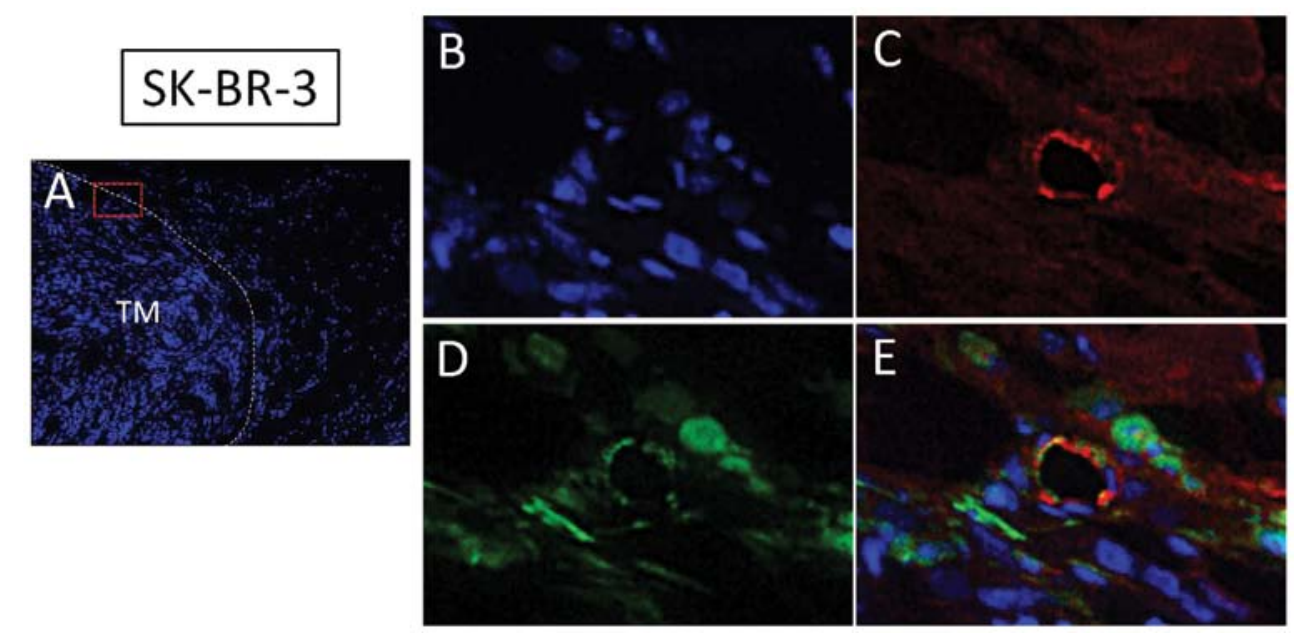

Figure 2. Human breast cancer SK-BR-3 cells recruit lymphatic endothelial lineage cells from bone marrow. Human breast cancer SK-BR-3 cells $\left(2 \times 10^{6}\right.$ cells) were xenografted to chimeric nude mice bearing GFP-positive bone marrow. Eight weeks after tumor implantation, mice were sacrificed and peritumoral tissues were histologically analyzed. (A) Representative images of tumor mass. (B-E) Representative lymphatic vessels around SK-BR-3 tumor mass, (B) stained with DAPI, (C) LYVE-1 (red), (D) GFP (green) and (E) merge images of C and D. Results shown are representative from 5 mice. DAPI, 4',6-diamidino2-phenylindole; LYVE-1, hyaluronic acid receptor-1; GFP, green fluorescent protein.

then the significance of differences in multiple comparisons was determined using Scheffe's multiple comparison test. $\mathrm{P}<0.01$ was considered statistically significant.

\section{Results}

Human colorectal cancer LS174T cells promote lymphangiogenesis and incorporation of bone marrow-derived cells in tumor lymphatics. We developed a tumor xenograft experimental model using chimeric nude mice with GFP-positive bone marrow cells in order to identify the contribution of marrow-derived cells in tumor lymphangiogenesis (11). Human colorectal cancer LS174T cells were subcutaneously implanted in this chimeric nude mouse model. LS174T cells formed tumor mass (Fig. 1A) three weeks after inoculation and a tumor lymphatic-rich microenvironment as detected by
LYVE-1 (Fig. 1B and C). LYVE-1-positive tumor lymphatics were located not only in peritumoral tissues but also in intratumoral tissue. Consistent with the locations of tumor lymphatics, GFP-positive cells from bone marrow were detected in peritumoral and intratumoral (Fig. 1D) tissues. Nearly $60 \%$ of LYVE-1-positive cells co-expressed GFP (Fig. 1E). These results suggest the possible involvement of bone marrowderived cells in tumor lymphangiogenesis.

Human breast cancer $S K-B R-3$ cells promote lymphangiogenesis and incorporation of bone marrow-derived cells in tumor lymphatics. In the same chimeric nude mouse model, SK-BR-3 human breast cancer cells were subcutaneously injected. At 8 weeks after inoculation, SK-BR-3 human breast cancer cells formed a tumor mass (Fig. 2A) and a tumor lymphatic-rich microenvironment as detected by LYVE-1 (Fig. 2B and C). 


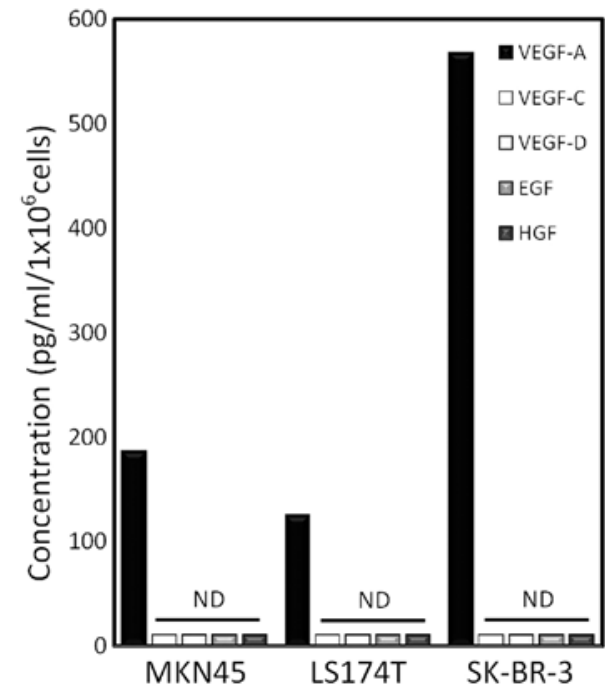

Figure 3. Human gastric cancer MKN45 cells, colorectal cancer LS174T and breast cancer SK-BR-3 cells predominantly produce VEGF-A. Human adenocarcinoma cells were cultured for $72 \mathrm{~h}$. Growth factors (VEGF-A, VEGF-C, VEGF-D, EGF and HGF) in the culture medium were analyzed by specific ELISA assay. ND, not detected in the assay systems. The results are expressed as means \pm SEM from 6 separate experiments. VEGF, vascular endothelial growth factor; EGF, epidermal growth factor; HGF, hepatocyte growth factor.

GFP-positive cells from bone marrow were also located at peritumoral lymphatic tissues (Fig. 2D). Nearly 50\% of LYVE1-positive cells co-expressed GFP (Fig. 2E). These data also support the hypothesis that bone marrow-derived lymphatic endothelial progenitor cells are involved in the tumor lymphangiogenesis in addition to pre-existing lymphatics.

Human malignant adenocarcinoma cells predominantly secrete $V E G F-A$. In order to identify the growth factor(s) involved in the lymphangiogenesis in the peritumoral tissues, human gastric cancer MKN45, colorectal cancer LS174 and breast cancer SK-BR-3 cells were cultured in vitro and growth factors in the culture medium were measured by specific ELISA assay. Among the growth factors tested, these three cell lines predominantly produced VEGF-A at $72 \mathrm{~h}$ after incubation (Fig. 3). The well-characterized lymphangiogenic factors (2,3,6-8), VEGF-C and VEGF-D, were below the detectable levels in the present ELISA assay. Furthermore, secretion of other growth factors, which are implicated in lymphangiogenesis and angiogenesis $(18,19)$, EGF and HGF, was not detected in these cells.

VEGF-A induces differentiation of bone marrow mononuclear cells into lymphatic progenitor cells. The present and previous (11) results suggest that VEGF-A-rich human adenocarcinomas recruit lymphatic epithelial progenitor cells from bone marrow. We further examined whether VEGF-A directly induced the differentiation of bone marrow mononuclear cells into lymphatic epithelial progenitor cells. First, bone marrow mononuclear cells were cultured in the absence or presence of VEGF family proteins and the relative expression of LYVE-1, a specific lymphatic endothelial marker, was analyzed. VEGF-A significantly increased LYVE-1 mRNA in bone marrow cells at $6 \mathrm{~h}$ after administration (Fig. 4). At the same time, VEGF-C

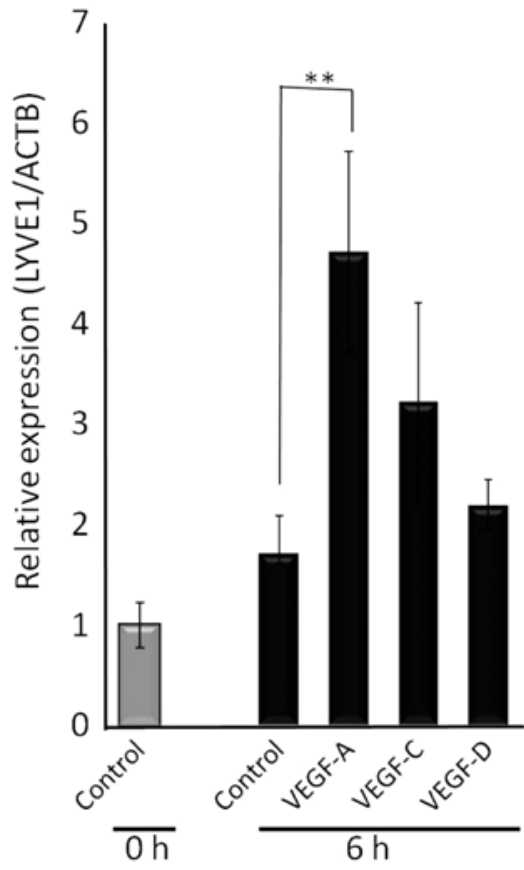

Figure 4. Expression of LYVE-1 mRNA in bone marrow mononuclear cells C57BL/6J mouse bone marrow mononuclear cells were cultured for $6 \mathrm{~h}$ in the absence or presence of VEGF-A $(50 \mathrm{ng} / \mathrm{ml})$, VEGF-C $(150 \mathrm{ng} / \mathrm{ml})$ or VEGF-D (150 ng/ml). The relative transcriptional expression of LYVE-1 mRNA was assessed by quantitative real-time PCR using ACTB/ $\beta$-actin as an internal control. The results are expressed as means \pm SEM from 5 separate experiments. ${ }^{* *} \mathrm{P}<0.01$. LYVE-1, hyaluronic acid receptor-1; VEGF, vascular endothelial growth factor.

and VEGF-D tended to increase LYVE-1 mRNA, yet the increase was not statistically significant. To further confirm VEGF-A-dependent differentiation of bone marrow mononuclear cells into lymphatic endothelial lineage cells, bone marrow cells were incubated with VEGF-A and immunostained with antibody against LYVE-1. In the control culture without VEGF family proteins, most of the attached cells were positive for CD34, a marker of hematopoietic and vascular endothelial progenitor cells (data not shown), but negative for LYVE-1 (Fig. 5A). The well-characterized lymphangiogenic factors, VEGF-C (Fig. 5B) and VEGF-D (Fig. 5C), stimulated the expression of LYVE-1 in bone marrow mononuclear cells in this analysis system after incubation for $40 \mathrm{~h} ; 50-60 \%$ cells were positive for LYVE-1. VEGF-A also clearly induced the increase of LYVE-1 positive bone marrow mononuclear cells (Fig. 5D). Nearly 60\% of cells became positive for LYVE-1 at $40 \mathrm{~h}$ after incubation. These results suggest the differentiation of bone marrow mononuclear cells into lymphatic endothelial lineage cells in response to VEGF-A.

\section{Discussion}

The formation of a lymphatic vascular system is a dynamic process during embryogenesis. In embryos, the blood circulatory system is first to evolve, followed by specification of lymphatic endothelial progenitor cells differentiated from blood vascular endothelial cells and budding of these cells from the cardinal vain (20). Under normal physiological postnatal conditions, however, the formation of new lymphatic vessels 

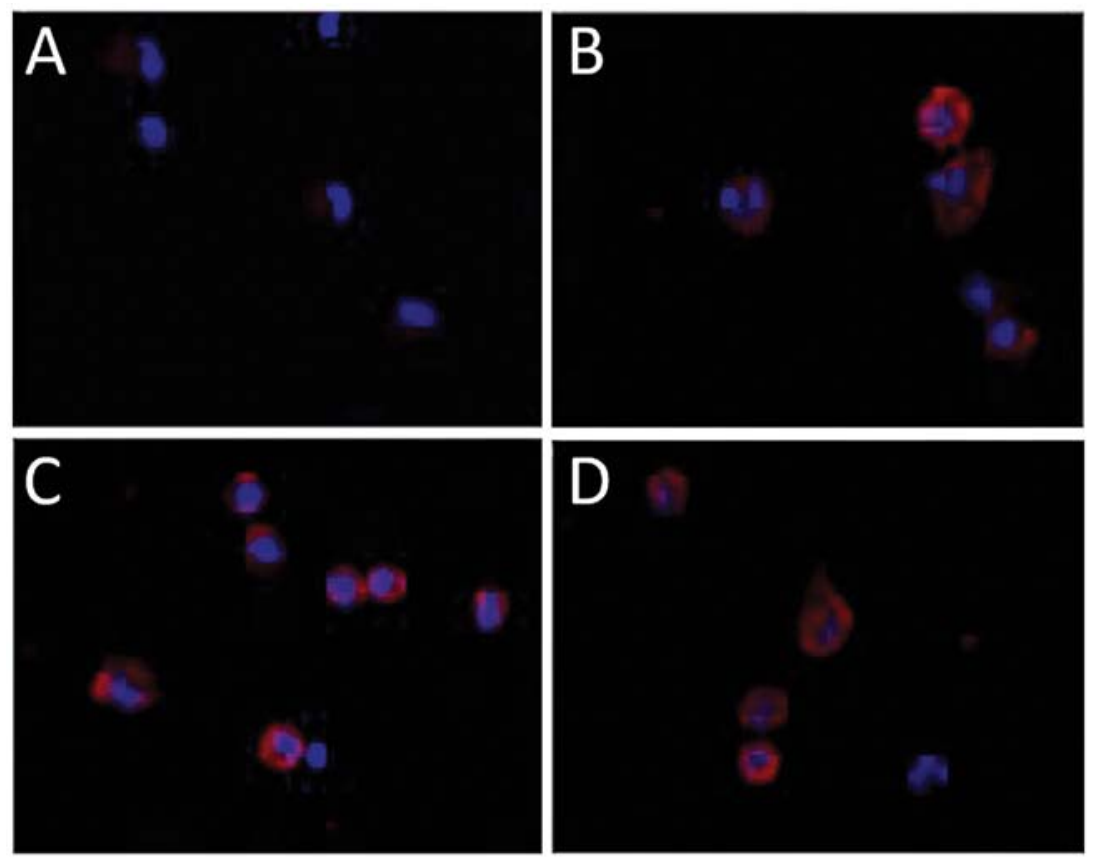

Figure 5. Differentiation of bone marrow mononuclear cells into lymphatic endothelial progenitor cells. C57BL/6J mouse bone marrow mononuclear cells were cultured for $40 \mathrm{~h}$ in the (A) absence or presence of (B) VEGF-C (150 ng/ml), (C) VEGF-D (150 ng/ml) or (D) VEGF-A (50 ng/ml). The cells were immunostained with antibody against a lymphatic epithelial marker, LYVE-1 (red). Results shown are representative from 5 separate experiments. VEGF, vascular endothelial growth factor; LYVE-1, hyaluronic acid receptor-1.

scarcely occurs. In adults, lymphangiogenesis only takes place during certain pathological conditions such as inflammation, tissue repair and tumor growth. Postnatal lymphatic vessel formations have been assumed to occur mainly by hyperplasia of lymphatic vessels themselves, or sprouting from preexisting lymphatics. The relative contribution to the formation of new vessels from circulating endothelial progenitor cells is not yet clearly understood. Integration of bone marrowderived cells into tumor lymphatics was initially denied in a mouse xenograft model with Lewis lung carcinoma or B16-F1 melanoma cells (21). In contrast, the involvement of bone marrow-derived cells in lymphatic vessel formation has been suggested in human kidney transplants (22) and mouse corneal lymphangiogenesis model (23). Moreover, the role of bone marrow progenitor cells in tumor lymphangiogenesis has recently been reported (23-25). We have previously shown that bone marrow-derived cells are involved in the formation of tumor lymphatics in a mouse xenograft model with human gastric cancer MKN45 cells (11). In the present study, we showed that in the same experimental model with chimeric nude mice bearing GFP-positive bone marrow, human colorectal cancer LS174T and breast cancer SK-BR-3 cells also recruited bone marrow-derived cells in the formation of tumor lymphatics. These results indicate that bone marrowderived lymphatic endothelial progenitor cells participate in the human adenocarcinoma-induced lymphangiogenesis in addition to pre-existing lymphatics.

Several factors with prolymphangiogenic activity have been identified to date $(2,3,20)$. These include VEGF-A, VEGF-C, VEGF-D and HGF. Attention has been focused on the role of VEGF-C and VEGF-D in recent years $(2,3)$. Using mouse models, overexpression of VEGF-C or VEGF-D has been shown to increase lymphatic vessel density, vessel diam- eter and lymph node and organ metastasis of many types of cancer (6-8). A role for VEGF-A in tumor-mediated lymphangiogenesis and metastasis has also been reported $(9,10)$. In the present study, three malignant adenocarcinomas examined predominantly secreted VEGF-A with minimal productions of VEGF-C and VEGF-D. Various types of human cancer cells extensively secrete VEGF-A and this ability is often associated with poor prognosis (26-29). VEGF-A is a key factor of new blood vessel formation (angiogenesis) to support tumor growth and metastatic dissemination $(26,27)$. Moreover, recent reports have demonstrated the immunosuppressive effects of VEGF-A by induction of regulatory $\mathrm{T}$ cells $(29,30)$ and by reduction of cytotoxic $\mathrm{T}$ cell activity (31).

Despite its initial recognition as a master regulatory molecule in angiogenesis $(26,27)$, previous studies indicated that VEGF-A also plays a role in lymphangiogenesis in tumor $(8,9)$, inflammation $(33,34)$ and wound healing $(35)$ models. VEGF-A may indirectly induce lymphangiogenesis via recruitment of VEGF-C/D producing macrophages (32). The role of VEGF-A appears to vary depending on the tissue microenvironment $(9,10,34,35)$. The data obtained in the present study show that the expression of a lymphatic endothelial-specific marker, LYVE-1, increased in in vitro culture of mouse bone marrow mononuclear cells in the presence of VEGF-A as assessed by immunostaining as well as real-time PCR. These results indicate that VEGF-A is able to directly promote differentiation of bone marrow mononuclear cells into lymphatic endothelial lineage cells.

In summary, the present study indicated that human malignant adenocarcinoma cells, which extensively secrete VEGF-A, promote tumor lymphangiogenesis in part via recruitment and incorporation of bone marrow-derived lymphatic endothelial progenitor cells into tumor lymphatics. The mechanism 
involves direct effect of VEGF-A on the differentiation of bone marrow mononuclear cells into lymphatic lineage cells.

\section{Acknowledgements}

This study was supported in part by an NaSNeLC research grant from Gifu University Graduate School of Medicine. The authors thank Ryoko Hayashi for her technical assistance.

\section{References}

1. Achen MG, Mann GB and Stacker SA: Targeting lymphangiogenesis to prevent tumour metastasis. Br J Cancer 94: 1355-1360, 2006.

2. Christiansen A and Detmar M: Lymphangiogenesis and cancer. Genes Cancer 2: 1146-1158, 2011.

3. Alitalo A and Detmar M: Interaction of tumor cells and lymphatic vessels in cancer progression. Oncogene 31: 4499-4508, 2012.

4. Banerji S, Ni J, Wang SX, Clasper S, Su J, Tammi R, Jones M and Jackson DG: LYVE-1, a new homologue of the CD44 glycoprotein, is a lymph-specific receptor for hyaluronan. J Cell Biol 144: 789-801, 1999.

5. Breiteneder-Geleff S, Soleiman A, Kowalski H, Horvat R, Amann G, Kriehuber E, Diem K, Weninger W, Tschachler E, Alitalo K and Kerjaschki D: Angiosarcomas express mixed endothelial phenotypes of blood and lymphatic capillaries: podoplanin as a specific marker for lymphatic endothelium. Am J Pathol 154: 385-394, 1999.

6. Mandriota SJ, Jussila L, Jeltsch M, Compagni A, Baetens D, Prevo R, Banerji S, Huarte J, Montesano R, Jackson DG, Orci L, Alitalo K, Christofori G and Pepper MS: Vascular endothelial growth factor-C-mediated lymphangiogenesis promotes tumour metastasis. EMBO J 20: 672-682, 2001.

7. Stacker SA, Caesar C, Baldwin ME, Thornton GE, Williams RA, Prevo R, Jackson DG, Nishikawa S, Kubo H and Achen MG: VEGF-D promotes the metastatic spread of tumor cells via the lymphatics. Nat Med 7: 186-191, 2001.

8. Skobe M, Hawighorst T, Jackson DG, Prevo R, Janes L, Velasco P, Riccardi L, Alitalo K, Claffey K and Detmar M: Induction of tumor lymphangiogenesis by VEGF-C promotes breast cancer metastasis. Nat Med 7: 192-198, 2001.

9. Nagy JA, Vasile E, Feng D, Sundberg C, Brown LF, Detmar MJ, Lawitts JA, Benjamin L, Tan X, Manseau EJ, Dvorak AM and Dvorak HF: Vascular permeability factor/vascular endothelial growth factor induces lymphangiogenesis as well as angiogenesis. J Exp Med 196: 1497-1506, 2002.

10. Hirakawa S, Kodama S, Kunstfeld R, Kajiya K, Brown LF and Detmar M: VEGF-A induces tumor and sentinel lymph node lymphangiogenesis and promotes lymphatic metastasis. J Exp Med 201: 1089-1099, 2005.

11. Tawada M, Hayashi S, Osada S, Nakashima S and Yoshida K: Human gastric cancer organizes neighboring lymphatic vessels via recruitment of bone marrow-derived lymphatic endothelial progenitor cells. J Gastroenterol 47: 1057-1060, 2012.

12. Guadagni F, Witt PL, Robbins PF, Schlom J and Greiner JW: Regulation of carcinoembryonic antigen expression in different human colorectal tumor cells by interferon- $\gamma$. Cancer Res 50: 6248-6255, 1990.

13. Imai Y, Leung CK, Friesen HG and Shiu RP: Epidermal growth factor receptors and effect of epidermal growth factor on growth of human breast cancer cells in long-term tissue culture. Cancer Res 42: 4394-4398, 1982.

14. Koshikawa N, Yasumitsu H, Umeda M and Miyazaki K: Multiple secretion of matrix serine proteinases by human gastric carcinoma cell lines. Cancer Res 52: 5046-5053, 1992.

15. Hayashi S, Morishita R, Nakamura S, Yamamoto K, Moriguchi A, Nagano T, Taiji M, Noguchi H, Matsumoto K, Nakamura T, Higaki J and Ogihara T: Potential role of hepatocyte growth factor, a novel angiogenic growth factor, in peripheral arterial disease: downregulation of HGF in response to hypoxia in vascular cells. Circulation 100 (Suppl 19): II301-II308, 1999.

16. Asahara T, Masuda H, Takahashi T, Kalka C, Pastore C, Silver M, Kearne M, Magner M and Isner JM: Bone marrow origin of endothelial progenitor cells responsible for postnatal vasculogenesis in physiological and pathological neovascularization. Cir Res 85: 221-228, 1999.
17. Hayashi S, Sato N, Yamamoto A, Ikegame Y, Nakashima S, Ogihara T and Morishita R: Alzheimer disease-associated peptide, amyloid $\beta 40$, inhibits vascular regeneration with induction of endothelial autophagy. Arterioscler Thromb Vasc Biol 29: 1909-1915, 2009.

18. Kajiya K, Hirakawa S, Ma B, Drinnenberg I and Detmar M: Hepatocyte growth factor promotes lymphatic vessel formation and function. EMBO J 24: 2885-2895, 2005.

19. Hogan BM, Bos FL, Bussmann J, Witte M, Chi NC, Duckers HJ and Schulte-Merker S: ccbel is required for embryonic lymphangiogenesis and venous sprouting. Nat Genet 41: 396-398, 2009.

20. Alitalo K: The lymphatic vasculature in disease. Nat Med 17: 1371-1380, 2011.

21. He Y, Rajantie I, Ilmonen M, Makinen T, Karkkainen MJ, Haiko P, Salven P and Alitalo K: Preexisting lymphatic endothelium but not endothelial progenitor cells are essential for tumor lymphangiogenesis and lymphatic metastasis. Cancer Res 64: 3737-3740, 2004.

22. Kerjaschki D, Huttary N, Raab I, Regele H, Bojarski-Nagy K, Bartel G, Kröber SM, Greinix H, Rosenmaier A, Karlhofer F, Wick N and Mazal PR: Lymphatic endothelial progenitor cells contribute to de novo lymphangiogenesis in human renal transplants. Nat Med 12: 230-234, 2006.

23. Maruyama K, Ii M, Cursiefen C, Jackson DG, Keino H, Tomita M, Van Rooijen N, Takenaka H, D'Amore PA, SteinStreilein J, Losordo DW and Streilein JW: Inflammation-induced lymphangiogenesis in the cornea arises from CD11b-positive macrophages. J Clin Invest 115: 2363-2372, 2005.

24. Religa P, Cao R, Bjorndahl M,Zhou Z,Zhu Z and Cao Y: Presence of bone marrow-derived circulating progenitor endothelial cells in the newly formed lymphatic vessels. Blood 106: 4184-4190, 2005.

25. Zumsteg A, Baeriswyl V, Imaizumi N, Schwendener R, Ruegg C and Christofori G: Myeloid cells contribute to tumor lymphangiogenesis. PLos One 4: e7067, 2009.

26. Ferrara N: VEGF and the quest for tumour angiogenesis factors. Nat Rev Cancer 2: 795-803, 2002.

27. Hicklin DJ and Ellis LM: Role of the vascular endothelial growth factor pathway in tumor growth and angiogenesis. J Clin Oncl 23: 1011-1027, 2005

28. Lyden D, Hattori K, Dias S, Costa C, Blaikie P, Butros L, Chadburn A, Heissig B, Marks W, Witte L, Wu Y, Hicklin D, Zhu Z, Hackett NR, Crystal RG, Moore MA, Hajjar KA, Manova K, Benezra R and Rafii S: Impaired recruitment of bonemarrow-derived endothelial and hematopoietic precursor cells blocks tumor angiogenesis and growth. Nat Med 7: 1194-1201, 2001.

29. Wada J, Suzuki H, Fuchino R, Yamasaki A, Nagai S, Yanai K, Koga K, Nakamura M, Tanaka M, Morisaki T and Katano M: The contribution of vascular endothelial growth factor to the induction of regulatory T-cells in malignant effusions. Anticancer Res 29: 881-888, 2009.

30. Li B, Lalani AS, Harding TC, Luan B, Koprivnikar K, Huan Tu G, Prell R, VanRoey MJ, Simmons AD and Jooss K: Vascular endothelial growth factor blockade reduces intratumoral regulatory $\mathrm{T}$ cells and enhances the efficacy of a GM-CSF-secreting cancer immunotherapy. Clin Cancer Res 12: 6808-6816, 2006.

31. Gavalas NG, Tsiatas M, Tsitsilonis O, Politi E, Ioannou K, Ziogas AC, Rodolakis A, Vlahos G, Thomakos N, Haidopoulos D, Terpos E, Antsaklis A, Dimopoulos MA and Bamias A: VEGF directly suppresses activation of $\mathrm{T}$ cells from ascites secondary to ovarian cancer via VEGF receptor type 2 . Br J Cancer 107: 1869-1875, 2012.

32. Cursiefen C, Chen L, Borges LP, Jackson D, Cao J, Radziejewski C, D'Amore PA, Dana MR, Wiegand SJ and Streilein JW: VEGF-A stimulates lymphangiogenesis and hemangiogenesis in inflammatory neovascularization via macrophage recruitment. J Clin Invest 113: 1040-1050, 2004.

33. Halin C, Tobler NE, Vigl B, Brown LF and Detmar M: VEGF-A produced by chronically inflamed tissue induces lymphangiogenesis in draining lymph nodes. Blood 110: 3158-3167, 2007.

34. Kunstfeld R, Hirakawa S, Hong YK, Schacht V, LangeAsschenfeldt B, Velasco P, Lin C, Fiebiger E, Wei X, Wu Y, Hicklin D, Bohlen P and Detmar M: Induction of cutaneous delayed-type hypersensitivity reactions in VEGF-A transgenic mice results in chronic skin inflammation associated with persistent lymphatic hyperplasia. Blood 104: 1048-1057, 2004.

35. Hong YK, Lange-Asschenfeldt B, Velasco P, Hirakawa S, Kunstfeld R, Brown LF, Bohlen P, Senger DR and Detmar M: VEGF-A promotes tissue repair-associated lymphatic vessel formation via VEGFR-2 and the $\alpha 1 \beta 1$ and $\alpha 2 \beta 1$ integrins. FASEB J 18: 1111-1113, 2004. 